\title{
Alternative Face Masks Made of Common Materials for General Public: Fractional Filtration Efficiency and Breathability Perspective
}

\author{
Chenxing Pei ${ }^{1 \#,}$ Qisheng Ou${ }^{1 \#}$, Seong Chan Kim¹, Sheng-Chieh Chen ${ }^{2}$, David Y.H. Pui ${ }^{1,3 *}$ \\ ${ }^{1}$ Department of Mechanical Engineering, University of Minnesota, Minneapolis, MN 55455, USA \\ ${ }^{2}$ Department of Mechanical and Nuclear Engineering, Virginia Commonwealth University, Richmond, VA 23284, USA \\ ${ }^{3}$ School of Science and Engineering, The Chinese University of Hong Kong, Shenzhen, Guangdong 518172, China
}

\begin{abstract}
As COVID-19 pandemic has caused more than 24 million confirmed cases globally (as of August $28^{\text {th }}, 2020$ ), it is critical to slow down the spreading of SARS-CoV-2 to protect the healthcare system from overload. Wearing a respirator or a mask has been proven as an effective method to protect both the wearer and others, but commercially available respirators and masks should be reserved for healthcare workers under a currently desperate shortage. The use of alternative materials becomes an option for the general public to make the do-it-yourself (DIY) masks, with their efficacy seldom reported. In this study, we tested commercial respirators and masks, furnace filters, vacuum cleaner filters, and common household materials. We evaluated the materials' fractional filtration efficiency and breathing resistance, which are primary factors affecting respiratory protection. To compare the efficiency-resistance tradeoff, the figure of merit of each tested common material was also calculated. Filter media with electrostatic charges (electret) is recommended due to its high efficiency with low flow resistance; multiple-layer household fabrics and sterilization wraps are acceptable materials; a coffee filter is inadvisable due to its low efficiency. The outcome of this study can not only offer guidance for the general public under the current pandemic but also suggest the appropriate alternative respiratory protection materials under heavy air pollution episodes.
\end{abstract}

Keywords: Respirator; Mask; Common material; Fractional efficiency; Breathability.

\section{INTRODUCTION}

COVID-19 was characterized as a pandemic by World Health Organization (WHO) on March 11, 2020, and it is a global challenge for the world. As an infectious disease that is mainly transmitted through droplets, the appropriate respiratory protection could protect the healthy population from infection (NASEM, 2020; WHO, 2020b). Respiratory protection is especially critical for frontline healthcare workers, who need to contact COVID-19 patients directly. When one wears a mask, the mask can help reducing virus spreading by capturing most of emitted droplets during speaking, sneezing, and coughing (van der Sande et al., 2008; Rengasamy et al., 2010; Davies et al., 2013; Anfinrud et al., 2020; Greenhalgh et al., 2020); on the other hand, the mask can offer effective protections by filtering virus-laden particles in the air

\footnotetext{
${ }^{\text {\#}}$ These authors contributed equally to this work.

* Corresponding author.

Tel.: +1-612-625-2537

E-mail address: dyhpui@umn.edu
}

(Johnson et al., 2009; Lai et al., 2012; Zuo et al., 2013; Leung et al., 2020b; Wang and Yu, 2020). Therefore, the priority is to ensure that frontline healthcare workers are protected well. However, the COVID-19 pandemic has led to the personal protective equipment (PPE) shortage, especially the respirators and masks. Therefore, various efforts have been paid to allocate available respirators and masks inventory for frontline healthcare workers, including decontamination (Liao et al., 2020; Ou et al., 2020).

As COVID-19 is infectious, it is critical to curbing the spread to protect the healthcare system from overload, socalled flattening the curve. It has been found that asymptomatic infected people and pre-symptomatic infected people could be potentially infectious sources (CDC, 2020a; National Health Commission and National Administration of Traditional Chinese Medicine, 2020). On the other hand, it is equally important for the general public to wear masks or equivalent face coverings to slow down the spread of the virus (CDC, 2020c, National Health Commission, 2020). As many states are re-starting and social activities are recovering in the United States, many governors across the country issued orders requiring face coverings when social distancing is unable to maintain (Littler Mendelson, 2020). WHO updated its advice on the masks use on June 5, which encourages the 
general public masking when physical distancing cannot be maintained (WHO, 2020a).

However, it has been an ongoing debate about whether universal masking is necessary. As early as Mar $2^{\text {nd }}, 2020$, there is a correspondence on the Lancet, discussing the necessity of wearing masks in community settings and mentioning that WHO was not recommending it due to lack of evidence. Authors emphasized that "absence of evidence of effectiveness should not be equated to evidence of ineffectiveness, especially when facing a novel situation with limited alternative options" (Leung et al., 2020a). A similar concern was also raised by Morawska and Cao (2020), where authors called on considering the possible airborne transmission. On July $6^{\text {th }}, 239$ scientists signed an open letter to the WHO to address the airborne transmission of COVID19, which is published in Clinical Infectious Diseases (Morawska and Milton, 2020). Later, WHO announced in a press conference that WHO plans to update its guidelines recently. This discussion brings up the question that how respirators and masks can protect wearers from the possible airborne transmission of COVID-19.

Whereas, considering the current desperately shortage of commercially available masks and respirators, the use of common materials to substitute masks for the general public is the only option, such as scarves and bandanas. Also, the Centers for Disease Control and Prevention (CDC) offers the tutorial for homemade masks (CDC, 2020c). It has been studied that homemade masks could not only protect the others from the wearer by reducing the amount of the respiratory droplets exhaled from the wearer but also offer protection to the wearer from inhaling virus attached particles (Cooper et al., 1983; van der Sande et al., 2008; Rengasamy et al., 2010; Davies et al., 2013; MacIntyre et al., 2015; Anfinrud et al., 2020; Bae et al., 2020; Howard et al., 2020; Konda et al., 2020; Leung et al., 2020a; Mueller et al., 2020; Prather et al., 2020; Zhao et al., 2020). However, common fabrics, such as T-shirts, cotton cloth, were the most often used materials, which is not as good as commercial masks (CDC, 2020b) How the general public could make good use of common materials to improve their homemade masks? In this article, we tested several common materials besides common fabrics to help the general public to protect themselves and people they interact with. It is worth noting that conclusions drawn from this study can offer guidance for the general public under the current pandemic. They can also be generalized to do-it-yourself (DIY) air pollution protection gears when commercial respiratory protection equipment is not available.

\section{METHODS}

Respirators and masks efficiency and breathability are key performance factors, associated with the filtering effectiveness and the breathing resistance of a respirator or a mask. In this study, the fractional filtration efficiency and the pressure drop across the filter media were measured.

Air filtration is not as simple as sieving, and there are several filtering mechanisms, including inertial impaction, interception, diffusion, electrostatic deposition, etc. With different filtration mechanisms dominating particle size less than $0.1 \mu \mathrm{m}$ or particle size in the range of $0.3-1 \mu \mathrm{m}$, overall fractional filtration efficiency curve will be a U-shape (Spurny, 1986; Yang, 2012; Ou et al., 2017). The particle filtration efficiency strongly depends on the particle size (Spurny, 1986; Ou et al., 2017). The fraction filtration efficiency is defined as the number of particles of a given size penetrating the filter medium, divided by the total number of particles challenged on it.

The fractional filtration efficiency was reported in this study for comparing the performance of common materials with commercial respirators/masks and to screen potential candidate materials. The particle size with the least efficiency of the filter is the most penetrating particle size (MPPS), which depends on filter material itself as well its operating conditions. For the filter without electrical charges (so-called the mechanical filter, e.g., glassfiber HEPA media, engine intake filter media), the MPPS is about $0.1-0.3 \mu \mathrm{m}$. For the filter with electrical charges (so-called the electret filter, e.g., some furnace filters, N95) the MPPS is around $0.1 \mu \mathrm{m}$ or less. Common household materials that are not designed for filtration can have MPPS larger than $0.3 \mu \mathrm{m}$. Fractional filtration efficiency reported in this study was from $0.03 \mu \mathrm{m}$ to $1 \mu \mathrm{m}$, which covers possible MPPS of most of materials tested and offers the size-resolved material efficiency.

The pressure drop of filter media is a measure of the breathing resistance. The pressure drop across a filter media is proportional to the face velocity with which the fractional filtration efficiency is also correlated. Hence, to compare common materials fairly, the same face velocity should be used. In this study, we tested all materials at $10.5 \mathrm{~cm} \mathrm{~s}^{-1}$. This face velocity is calculated from $85 \mathrm{~L} \mathrm{~min}^{-1}$ flow rate and $135 \mathrm{~cm}^{2}$ filtration area. The flow rate of $85 \pm 4 \mathrm{~L} \mathrm{~min}^{-1}$ is used by the National Institute for Occupational Safety and Health (NIOSH) to certify N95. The filtration area of $135 \mathrm{~cm}^{2}$ is the lower end filtration area of commercial N95s. The lower filtration area results in a higher face velocity, which adversely affects the filtration efficiency. Hence, efficiency measurements in this study are conservative, representing the worst conditions that may occur. In this study, we used a differential pressure gauge (Dwyer, Michigan City, IN) to measure the pressure drop across the testing filter media. To ensure the stable and accurate filter face velocity and flowrate, several mass flow controllers (MKS Instruments, Inc. Andover, MA) controlled the flow in the fractional filtration efficiency measuring system.

There are different test standards for respirators and masks. NIOSH tests respirators according to 42 CFR part 84 (Office of the Federal Register, 1995). The challenging particle is neutralized $\mathrm{NaCl}$, whose count median diameter is 0.075 $\pm 0.020 \mu \mathrm{m}$ and the geometric standard deviation is less than 1.86. The testing flow rate is regulated to $85 \pm 4 \mathrm{~L} \mathrm{~min}^{-1}$ for one respirator. For the surgical mask, ASTM and FDA have different testing protocols for particle filtration efficiency and bacterial filtration efficiency. In general, the challenging particle of particle filtration efficiency is latex spheres, and the face velocity is defined in a broad range from $0.5 \mathrm{~cm} \mathrm{~s}^{-1}$ to $25 \mathrm{~cm} \mathrm{~s}^{-1}$. FDA guidance document for surgical mask $510(\mathrm{k})$ calculates the particle efficiency by $0.1 \mu \mathrm{m}$ latex spheres (FDA, 2003), while ASTM F2299 claimed a particle 
size range from 0.1 to $5.0 \mu \mathrm{m}$ (testing by monodisperse particles) (ASTM International., 2017). As for bacterial filtration efficiency, the FDA follows ASTM F2101 to test surgical masks (ASTM International, 2019). Staphylococcus aureus bacteria are used with the mean particle size at $3.0 \pm$ $0.3 \mu \mathrm{m}$. The testing flow rate is $28.3 \mathrm{~L} \mathrm{~min}^{-1}$. This study used the NIOSH protocol as a reference.

Electron micrographs of SARS-CoV-2 particles show that they are generally spherical, and their diameter is around 0.06 to $0.14 \mu \mathrm{m}$ (Zhu et al., 2020). The respiratory generated droplets could be several micrometers or larger, which will then evaporate to a smaller nucleus (Morawska, 2006; Morawska et al., 2009; Gralton et al., 2011; Bourouiba et al., 2014; Scharfman et al., 2016; Anfinrud et al., 2020; Bourouiba, 2020; Morawska and Cao, 2020). Therefore, the fractional filtration efficiency in this study $(0.03 \mu \mathrm{m}-1 \mu \mathrm{m})$ covered the size range for both the MPPS of common filter media and the SARS-CoV-2 particle cluster size range. The material filtration efficiency at its MPPS or SARS-CoV-2 size could offer a conservative evaluation of the material used. It is worth noting that as aforementioned, the fractional filtration efficiency curve is a U-shape, even the largest particle size used in this study is only $1 \mu \mathrm{m}$, the fractional filtration efficiency of several micrometers particle could be inferred to be higher than the efficiency at $1 \mu \mathrm{m}$. Therefore, if the MPPS is confirmed, the lowest efficiency is found.

This study did not test whole respirators/masks due to limited resources. Common materials tested in this study were not sewn, so all testing samples are cut to a $40 \mathrm{~mm}$ diameter disc to fit the filter holder. As aforementioned, the testing face velocity was kept the same as the whole respirators/masks testing, therefore the efficiency and pressure drop measurement are consistent. The filter holder used in this study hold the media by tightening the outside mounting nut, so it could adapt different materials' thickness and seal around the sample.

$\mathrm{NaCl}$ particles were selected as the challenging particle to align with the NIOSH testing protocols. $\mathrm{NaCl}$ submicron particles were generated by atomizing its solutions and then dried by a diffusion dryer. In this study, we measured the fractional efficiency with monodisperse $\mathrm{NaCl}$ particles, hence it is important to keep the particle number concentration high enough to get statistically meaningful efficiency measurement in the size range in this study $(0.03 \mu \mathrm{m}-1 \mu \mathrm{m})$. A pneumatic atomizer (TSI 3076, Shoreview, MN) was used in this study, with $0.4 \%$ volume concentration $\mathrm{NaCl}$ solution and 30 PSI ( $\approx 207 \mathrm{kPa}$ ) filtered compressed air. Fig. 1 shows the schematic diagram of the testing apparatus, which is the same as the one used in Ou et al. (2020).

The efficiency of filter media may change after challenging particles loaded on it, which could be mitigated by reducing the amount of the particles deposited on the filter media. However, the number concentration at the upstream should be high enough so that the efficiency measurement is statistically meaningful. Since we are measuring the fractional filtration efficiency, which allows us to measure the efficiency of a certain particle size at one time. By allowing only monodisperse particles with the size being measured to reach the filter, the loading effect could be mitigated and the number concentration is high enough at the same time. An Electrostatic Classifier (TSI 3080, Shoreview, MN) with a long Differential Mobility Analyzer (TSI 3081, Shoreview, $\mathrm{MN}$ ) classified the $\mathrm{NaCl}$ particle to the desired size. A Po-210 Staticmaster ${ }^{\circledR}$ Alpha Ionizer (NRD, LLC. Grand Island, NY) neutralizer brought the challenging particles to the Boltzmann charge equilibrium. The test filter was then challenged by neutralized monodisperse $\mathrm{NaCl}$ particles with a certain amount of dilution air to meet the face velocity requirement. An Ultrafine Condensation Particle Counter (UCPC, TSI 3776, Shoreview, MN) was connected to the upstream and downstream of the filter holder by a pneumatic switching three-way valve to measure corresponding concentrations.

The fractional filtration efficiency is calculated by the formula below.

Fractional Filtration Efficiency $=1-\frac{C_{\text {down }}}{C_{u p}} / \frac{C_{\text {blank }, \text { down }}}{C_{\text {blank }, u p}}$

$C_{d o w n}$ and $C_{u p}$ are the UCPC concentration measurement at

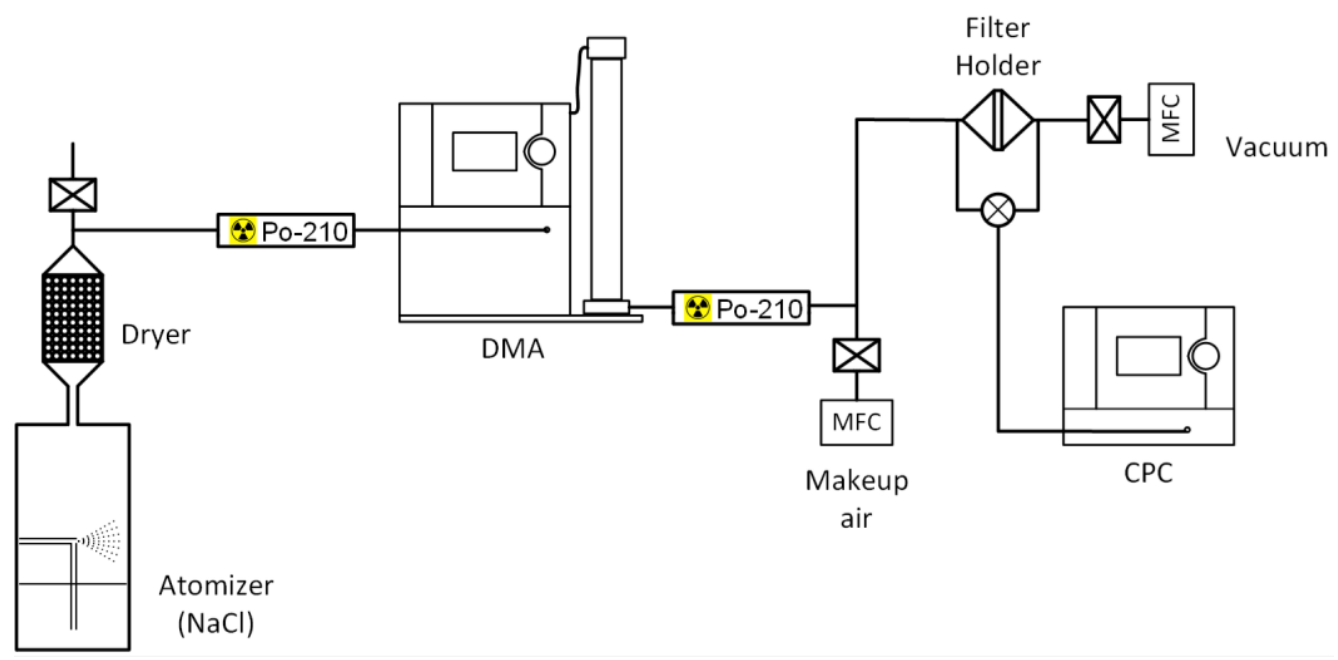

Fig. 1. Schematic of the fractional efficiency measurement setup. 
the upstream and downstream of the filter holder, respectively. $C_{\text {blank,down }}$ and $C_{\text {blank,up }}$ are concentration measurements without the test material in the filter holder, accounting for the system particle loss. Theoretically, Filter penetration could be calculated from the ratio of the downstream particle concentration and the upstream concentration. Hence the filtration efficiency is calculated from one minus the penetration. However, in practice, there are some system loss in measurement. When filter sample is not in place, the system loss could be measured. The upstream and downstream sampling length, geometry, and port location could cause slight difference in $C_{\text {blank,down }}$ and $C_{\text {blank,up }}$ concentration readings. This formula is incorporated with system loss.

Due to the time and resources constraint, all results reported in this article were the results from a single measurement. The standard deviation showing on fractional filtration efficiency plots are calculated from the particle concentration variation at the upstream and downstream based on error propagation. The purpose of this study is to offer a reference for the general public to select better alternative mask material. The sample-to-sample variation will not jeopardize final recommendations, besides, variations between the material the general public used and the material tested cannot be compensated by more replicates.

\section{RESULTS AND DISCUSSION}

\section{Commercial Respirators and Masks}

To study the efficacy of common materials filtering out the particles and droplets carrying SARS-CoV-2, available commercial respirators and masks were tested as the references in this study. As one of the best filtration research centers in the world, the Center for Filtration Research at the University of Minnesota received many test requests, and we also collected available masks and other common materials to screen potential face-covering candidates. Some masks received were not in its original package, so their information was insufficient, such as brands, efficiency ratings, etc. For simplicity, we named 10 masks with letters (Mask A to K). Besides 10 flat masks, a shaped KN95 respirator was received. 3MTM 8210 N95, 3M $\mathrm{M}^{\mathrm{TM}} 1820$ procedure mask, and KimberlyClark $^{\text {TM }} 47090$ procedure mask were tested from the lab PPE stockpile. This makes a total of 14 respirators/masks tested as the reference, which is representative of commercial respirators and masks.

The fractional filtration efficiency and breathing resistance of 14 respirators/masks are shown in Fig. 2. Fractional filtration efficiency curves could be categorized into two groups, electret media (blue shade) and non-electret media (orange shade). The lowest efficiency of the electret media mask is about $60 \%$ at $0.03 \mu \mathrm{m}$. The $3 \mathrm{M}^{\mathrm{TM}} 8210$ N95, KN95, and Mask A are all above $90 \%$ efficient. The overwhelming majority of electret masks fractional efficiencies fall in $70 \%-$ $85 \%$. The MPPSs of all electret media are below $0.1 \mu \mathrm{m}$. It could be found the fractional filtration efficiency of all electret media increases with greater particle size. The Mask $\mathrm{F}$ has the poorest performance among all electret, while the fractional filtration efficiency of the Mask F at $1 \mu \mathrm{m}$ reaches
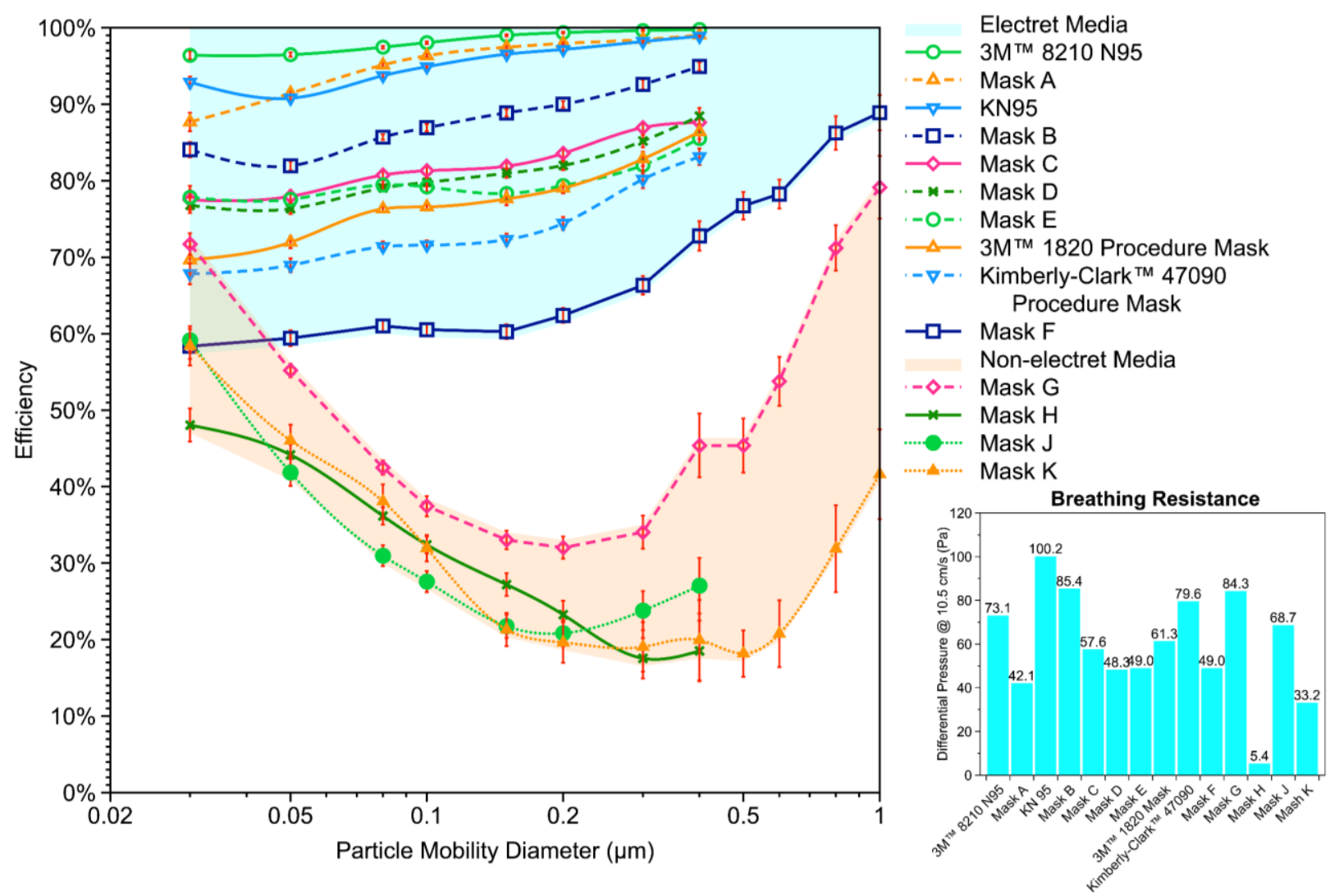

Fig. 2. Fractional filtration efficiency and breathing resistance of commercial respirators and masks. 
around $85 \%$ and will continue to increase beyond $1 \mu \mathrm{m}$. The non-electret media masks fractional efficiencies are significantly lower than that of the electret media mask and their MPPSs are about $0.3-0.4 \mu \mathrm{m}$. The fractional filtration efficiency at MPPS is as low as $20 \%$, while the fractional filtration efficiency increases towards both smaller and larger particles, showing a U-shape. The fractional filtration efficiency of the Mask K increases to $40 \%$ at $1 \mu \mathrm{m}$ particle size and it will continue to grow at larger sizes. The overwhelming breathing resistance of respirators and masks are in the $30 \mathrm{~Pa}$ to $100 \mathrm{~Pa}$ range, and Mask $\mathrm{H}$ is extremely low with only 5.4 Pa. The breathing resistance of all tested respirators and masks are in the acceptable range for normal breath.

To compare the common material to the commercial respirators and masks, the $3 \mathrm{M}^{\mathrm{TM}} 8210 \mathrm{~N} 95,3 \mathrm{M}^{\mathrm{TM}} 1820$ procedure mask, and Mask $\mathrm{J}$ will be plotted as references in common material fractional filtration efficiency and breathing resistance figures (Figs. 3-5 shown below). They represent the N95 level respirators, electret media masks, and nonelectret media masks.

\section{Furnace Filters}

Furnace filters are common material that are designed to filter out dust, pet dander, allergen, bacteria, and even virus in the room air. In this study, we collected four types of furnace filter: Filtrete ${ }^{\mathrm{TM}}$ MPR 1900, 2200, and 2800, and Arm \& HammerTM Air Filter. All four furnace filters are pleated and marketed as electret media filter. Filtrete ${ }^{\mathrm{TM}}$ MPR 1900 and 2200 are rated as MERV 13, this could be confirmed from their fractional filtration efficiency curves in Fig. 3. Filtrete ${ }^{\mathrm{TM}}$ MPR 2800 is rated as MERV 14 and has the highest efficiency (ASHRAE, 2017). For both Filtrete ${ }^{T M}$ MPR 1900, 2200, and 2800, their fractional efficiencies are higher than that of the $3 \mathrm{M}^{\mathrm{TM}} 1820$ procedure mask, a mask that is commonly used in hospital settings. As designed for handling a large amount of air circulation in residential or commercial buildings, the breathing resistances of single layer Filtrete ${ }^{\text {TM }}$ MPR 1900, 2200, and 2800 are significantly lower than the reference respirator/mask as shown in the bar chart in Fig. 3. Multiple-layer performance of collected furnace filters was also evaluated besides the single-layer measurements. The 5-layer Filtrete ${ }^{\mathrm{TM}} \mathrm{MPR} 1900,2200$, and 2800 perform comparably to $3 \mathrm{M}^{\mathrm{TM}} 8210$ N95 respirators in terms of efficiency and breathing resistance. It can be found that the pressure drop of 5-layer media is about 10 times of the single layer media, with the reason being the thickness of the stacked multi-layer filter media is reduced due to the pressing seal nature of the filter holder. The stacked fluffy media is compressed so that its permeability is reduced. The fractional filtration efficiency curve of 2-layer Arm \& Hammer ${ }^{\mathrm{TM}}$ Air Filter is slightly lower than that of the $3 \mathrm{M}^{\mathrm{TM}}$ 1820 procedure mask, while much better than that of the Mask J. Its $1 \mu \mathrm{m}$ particle efficiency is above $80 \%$ and the efficiency could be higher for even larger particle size. Its breathing resistance is only $10.3 \mathrm{~Pa}$, about $1 / 6$ of the $3 \mathrm{M}^{\mathrm{TM}}$ 1820 procedure mask.

\section{Vacuum Cleaner Filters}

Vacuum cleaner filters are another common air filter. We tested three grades of pleated vacuum cleaner filters and one

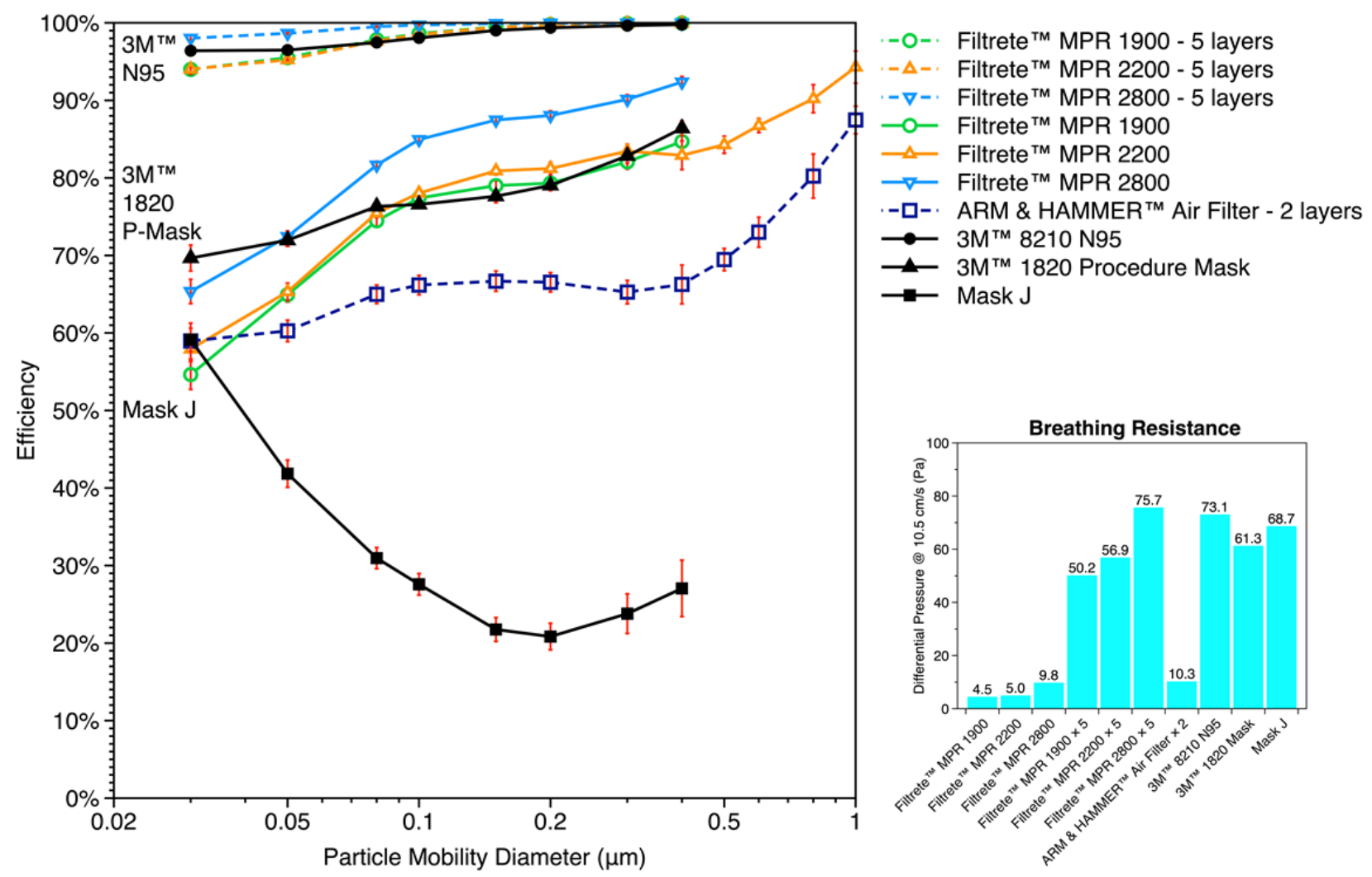

Fig. 3. Fractional filtration efficiency and breathing resistance of furnace filters. 

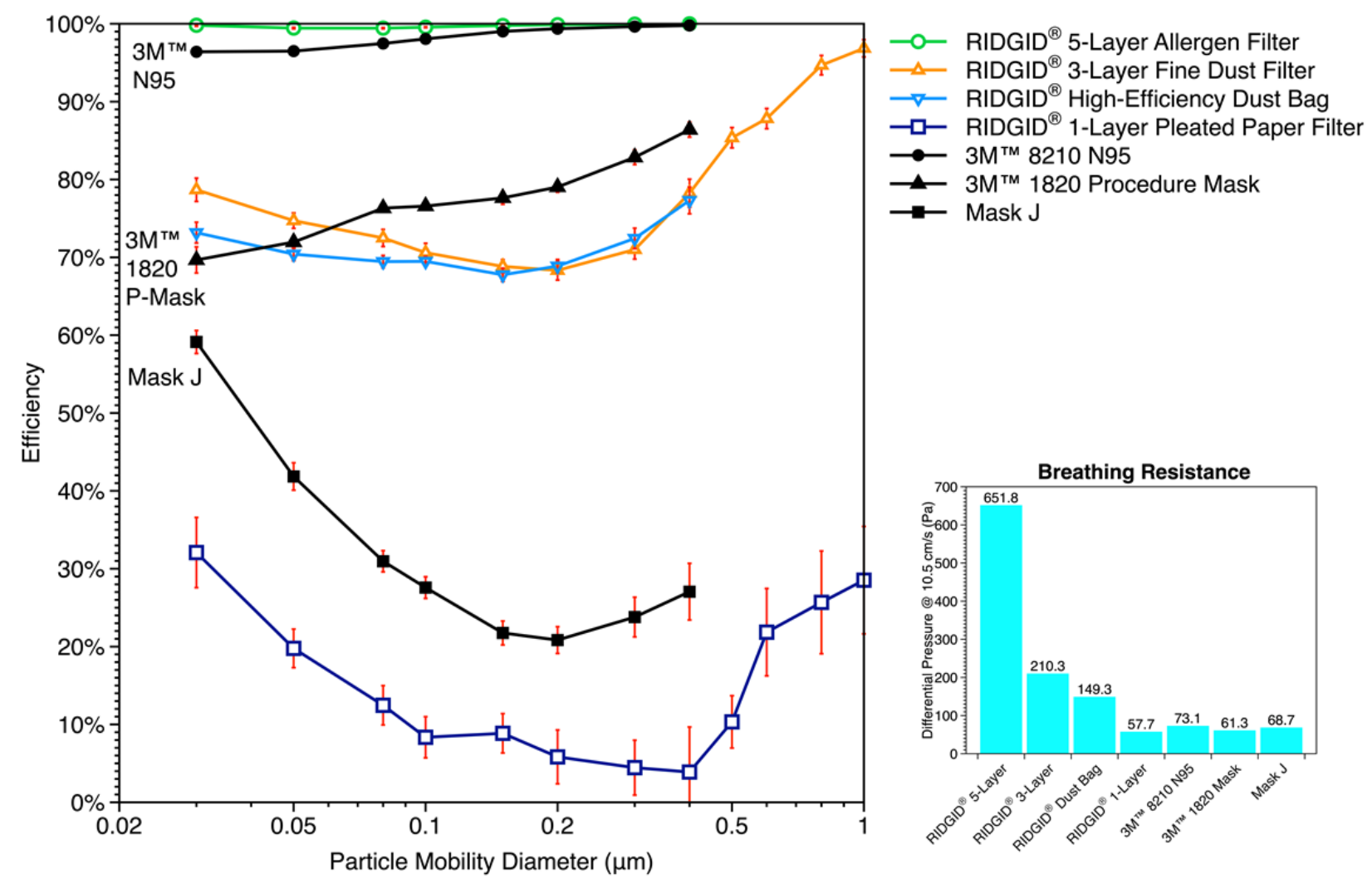

Fig. 4. Fractional filtration efficiency and breathing resistance of vacuum cleaner filters.

vacuum cleaner filter bag, and their results are showing in Fig. 4. The Ridgid ${ }^{\circledR}$ 5-Layer Allergen Vacuum Cleaner Filter could offer protection even better than N95 respirator. However, its breathing resistance is about 10 times of the N95, which is impractical to be used as an alternative respirator/mask material. If it was molded as a tight-fitting respirator, just like the commercial N95 mask, the breathing resistance would be twice of the breathing resistance requirement (343 Pa) indicated in $42 \mathrm{CFR}$ Part 84 . On the other hand, if this material was used to make a loose-fitting mask, the overall efficacy of the mask will be largely jeopardized since a large portion of the inhaled air would leak through the non-sealed edge rather than flow through the media because of differential pressure balancing. With a similar fractional filtration efficiency as the procedure mask, the breathing resistance of the Ridgid ${ }^{\circledR}$ Fine Dust Vacuum Cleaner Filter and the Ridgid ${ }^{\circledR}$ High-efficiency Dust Bag is about triple and double of the procedure mask. However, the efficiency of Ridgid ${ }^{\circledR}$ 1-Layer Pleated Paper Filter is even worse than the Maks $\mathrm{J}$, although breathing resistance is slightly lower than that of Mask J.

\section{Common Household Materials}

We also tested some common household materials to assess their potential as alternative respirator/mask materials, and their results are showing in Fig. 5. The comparison could offer a filtration efficiency and breathing resistance perspective on candidate common material of homemade masks. We tested several kinds of material, including sterilization wrap, household fabrics, paper products, which are representatives of materials that have been widely mentioned recently as DIY mask materials.

We tested two sterilization wraps that are designed for sterilized instrument wrapping, Halyard H600 and CardinalHealth $^{\mathrm{TM}}$ CH600. The sterilization wraps were designed for blocking bacteria while allowing gas penetration. They are composed of multiple layers of spunbond and meltblown materials; both are widely used as air filtration media. Therefore, they share a similar structure with air filters, which helps in particle filtration. Electric charges were applied on Halyard H600 to enhance particle capture capabilities, according to the manufacturer, which is one of the reasons that the fractional filtration efficiency of Halyard $\mathrm{H} 600$ is higher than that of CardinalHealth ${ }^{\mathrm{TM}} \mathrm{CH} 600$ which does not have electric charges according to our tests. The breathing resistance of Halyard $\mathrm{H} 600$ and CardinalHealth ${ }^{\mathrm{TM}}$ CH600 are about 2 and 3 times of that for $3 \mathrm{M}^{\mathrm{TM}} 1820$ procedure mask, respectively.

Four common fabrics were tested to offer the scientific support in material selections: 2-layer Thinsulate ${ }^{\mathrm{TM}}$, and 5-layer bed sheets, T-shirts, and Swiffer ${ }^{\circledR}$ Sweeper ${ }^{\circledR}$. Their fractional filtration efficiency curves are comparable, and MPPSs are around $0.3 \mu \mathrm{m}$ with $50 \%$ efficiency at MPPSs. Thinsulate ${ }^{\mathrm{TM}}$ is intended to offer insulation while keeping the moisture penetration, which is achieved by high porous microfibers, an essential microstructure of air filters. The efficiency of 2layer Thinsulate ${ }^{\mathrm{TM}}$, therefore, could be comparable to that of 5-layer the other three materials. Swiffer ${ }^{\circledR}$ Sweeper $^{\circledR}$ is electrostatically charged so that it can pick up and retain small dust and debris when used to swipe off household 

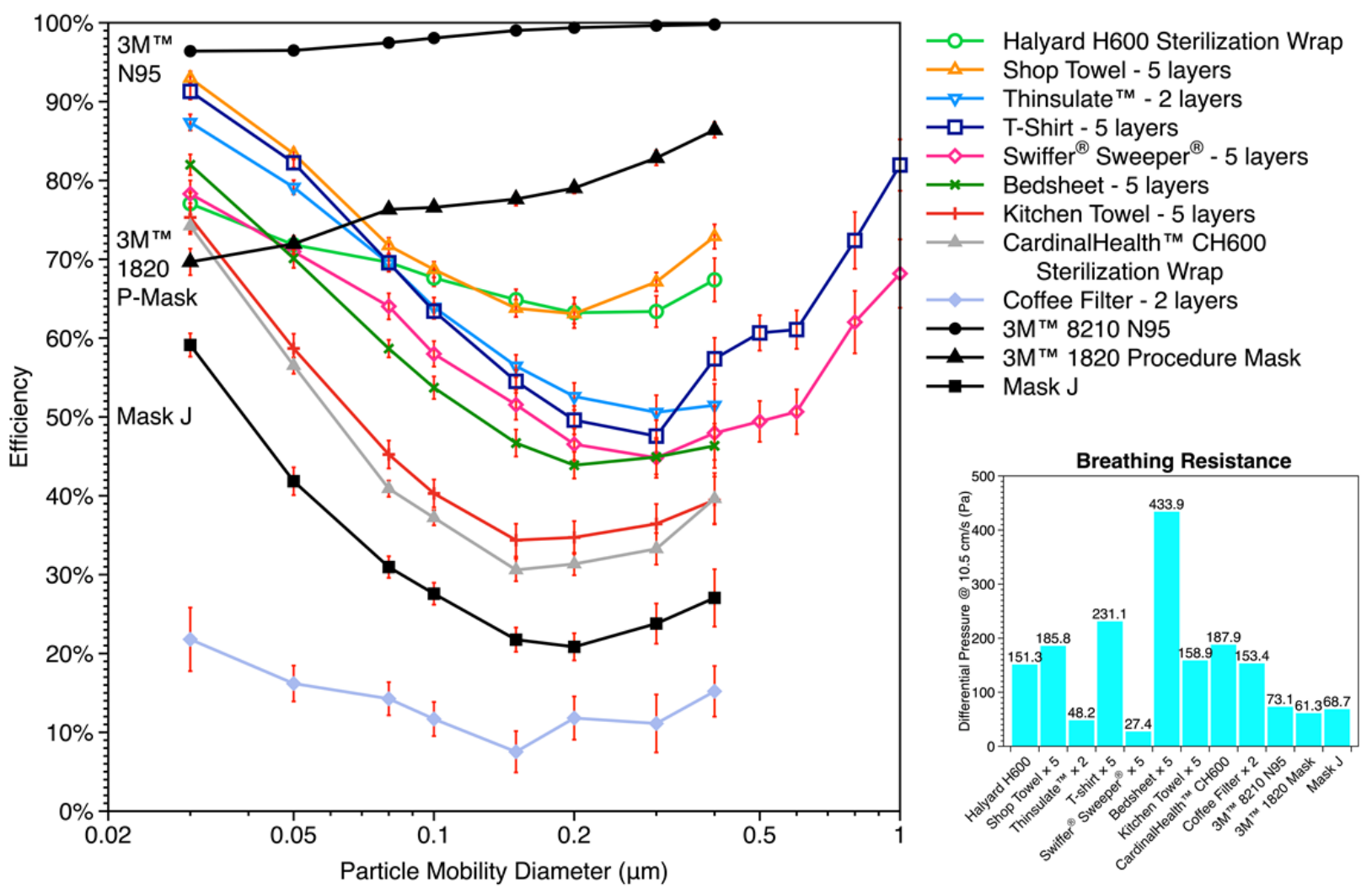

Fig. 5. Fractional filtration efficiency and breathing resistance of common fabrics.

surfaces. It filters out particles like an electret media, but the charge level on it is not as strong as commercial electret filters (e.g., respirators, face masks, furnace filters) so that its MPPS is still $0.3 \mu \mathrm{m}$, which is also partially attributed to its larger fiber size than most commercial electret filtration materials. 5-layer bedsheets and T-shirts tested in this study have similar efficiencies, which are $\sim 50 \%$ efficient at $300 \mathrm{~nm}$, suggesting that stacking sufficient layers of similar fabric materials are necessary to ensure desired respiratory protection to the wearer, while simply pulling the collar band above the nose is not recommended. From the breathing resistance perspective, the breathing resistance of Thinsulate ${ }^{\mathrm{TM}}$ and Swiffer $^{\circledR}$ Sweeper $^{\circledR}$ is only about $75 \%$ and $50 \%$ of that for $3 \mathrm{M}^{\mathrm{TM}} 1820$ procedure mask, respectively. Their efficiency could be further improved by adding more layers, where the increased material thickness can be a concern. Additionally, known as an excellent thermal insulator, the advantage of Thinsulate ${ }^{\mathrm{TM}}$ in its original duty now pose a disadvantage for it being used as a face mask material. Exhaling through mouth and nose is one of the major routes for the human to expel the body heat, where good thermal insulation is not welcome. As the easiest accessible materials in a household, 5-layer bedsheets and T-shirts tested in this study have significantly higher breathing resistance than their procedure mask reference, making them less recommended from breathability and facial-leak points of view. Paper products are also discussed widely as the candidates for alternative masks. The efficiencies of a 5-layer shop towel and kitchen towel are in between of the $3 \mathrm{M}^{\mathrm{TM}} 1820$ procedure mask and Mask J. Again, the multiple-layered configuration is the key for adequate self-protection. One of the concerns of using paper products is their breathing resistance, which is high from the measurement and may increase further after gradually picking up moisture from human exhalation. Coffee filters, though the only material in this group with a "filter" in its name, is the last material to be considered as an air-filtering face mask, owing to its combination of exceptionally low efficiency and higher-than-average breathing resistance.

\section{Discussion of the Figure of Merit}

The above discussions about fractional filtration efficiency and breathing resistance of common materials recommended the candidates for the alternative mask materials. However, it is still hard to compare two materials if one has high efficiency, high breathing resistance, and the other one has low efficiency and low breathing resistance. The figure of merit (Brown, 1993) is therefore introduced to compare two materials under the same standards. The figure of merit of filter material can be calculated as

$$
F O M=-\frac{\ln (1-E)}{\Delta P}
$$

where $\mathrm{E}$ is the filter efficiency and $\Delta \mathrm{P}$ is the differential pressure. The figure of merit represents the level of particle capturing a filter media can achieve per unit of flow resistance penalty, which accounts for the efficiency and breathing resistance (differential pressure) concurrently, so that it can be used to compare the efficiency-resistance tradeoff among 
all the materials tested. Fig. 6 shows the figure of merit of the selected materials.

The first tier consists of four materials carrying electrostatic charges. The figure of merit of Filtrete ${ }^{\mathrm{TM}}$ MPR2200 and MPR 2800 are even higher than 3MTM 8210 N95. It should be noticed that Filtrete ${ }^{\mathrm{TM}}$ MPR2800 ranked higher than Filtrete $^{\text {TM }}$ MPR2200 in terms of efficiency, but its figure of merit is slightly lower than that of Filtrete ${ }^{\mathrm{TM}}$ MPR2200 due to its higher breathing resistance. The other two materials, Swiffer $^{\circledR}$ Sweeper $^{\circledR}$ (5 layers) and Thinsulate ${ }^{\mathrm{TM}}$ (2 layers), have a similar figure of merit as $3 \mathrm{M}^{\mathrm{TM}} 1820$ procedure mask. All four first-tier materials are the most-recommended candidates from the filtration point of view. The second tier includes another four materials: Halyard H600 sterilization wrap, RIDGID ${ }^{\circledR}$ 3-layer Fine Dust Filter, and T-Shirt (5 layers) have a similar figure of merit, which is comparable to that of the Mask J, a non-electret commercial mask. These results show that the quality of those three common materials as good as the Mask J. It could be found that the efficiencies of the above three materials are much higher than that of the Mask J, at least 30 percentage points (5-layer T-shirt) at MPPS. Therefore, the comparable figure of merit to Mask $\mathrm{J}$ is mainly because of the high breathing resistance of three common materials. The figure of merit of 5-layer bedsheet is lower than the other three, the likely reason is that the breathing resistance of the bedsheet we tested was about double that of the T-shirt. The inadvisable material is coffee filters, which is ranked lowest in both efficiency plot and figure of merit plot. Even it is called coffee filter, it is designed to separate the ground coffee from water, having hundreds of times larger size than the SARS-CoV-2 virus or other air-borne pathogens a mask needs to filter out. Although counter-intuitive at first glance, it needs to be recognized that furnace filters and vacuum filters may work well as alternative mask materials, but coffee filters do not work well.

\section{Some Discussions}

Some of the recommended materials can be cut and sewn to a mask, such as T-shirts, bedsheets. However, some material is hard to be processed in the same way, such as furnace filters, Swiffer ${ }^{\circledR}$ Sweeper ${ }^{\circledR}$. A combination of a cloth mask and a filter material insert is therefore recommended. A cloth mask could be made following various instructions online (CDC, 2020b). The face-covering part can be made into a double-layer design with a slit on the inner side, where a filter material can be cut and inserted to boost the filtration efficiency. This makes the use of those difficult-to-sew materials, such as furnace filters, possible and it can also reduce the material consumption by using small pieces only covering the size of the insert pocket.

This study evaluated common materials that have the potential to be made into alternative masks for the general public under the current COVID-19 pandemic as an emergency option. It should be noticed that this study does not endorse the safety of using the studied material as an alternative mask. For example, fiber shedding could be potential harm to wearer, especially people who have underlying respiratory conditions. Many of the tested materials in this study were not intended for respiratory protection so that potential fiber

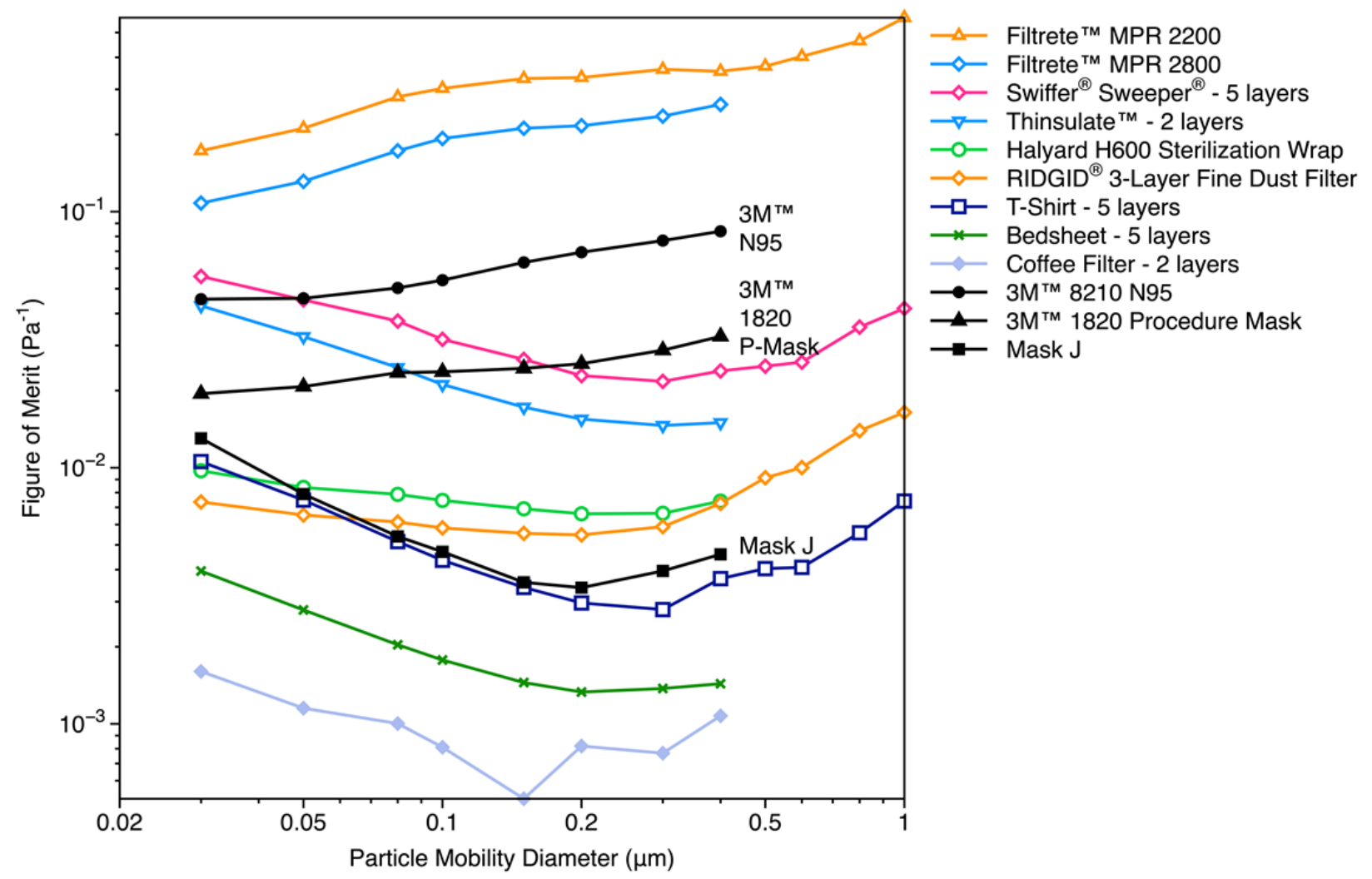

Fig. 6. The figure of merit of common materials. 
shedding was not tested by their manufacturers or certification agencies. With the tide of DIY masks using alternative materials, some manufacturers announced the notice regarding altering their products to mask use. For example, $3 \mathrm{M}$ does not recommend altering the furnace filter to other usages (3M, 2020); Halyard claims that they cannot recommend the off-label use of the sterilization wrap (Halyard, 2020); Ridgid has a similar notice that their vacuum filter and vacuum filter bag is not designed as a respiratory protection material (RIDGID, 2020).

In this study, different commercial respirators, masks, and common materials were all tested with a sealed filter holder and the same face velocity, to ensure a fair performance comparison of the materials themselves. When a filter material is made into a respirator or mask, even the tightfitting respirator design experiences various degrees of a facial leak, due to design faults, the variation of wear's facial profiles, and improper use. Such leak is more substantial on loose-fitting face mask designs, which most DIY masks are. Face leak causes a certain portion of air inhaled not filtered by mask materials, resulting in lower overall efficacy than the material efficiency as reported in this study, the degree of which varies largely among mask shape/style designs and material's breathing resistance For similar mask designs, the pressure-driven face leak is severer on masks made of materials with higher resistance, which emphasizes another reason why breathing resistance is treated equally important to filtration efficiency in this study, other than the consideration of breathability and wearer's comfort. The figure of merit is a well-accepted indicator of efficiency-resistance balance in filtration society, but its correlation with the overall efficacy of a face mask (with face leak counted) is not fundamentally or experimentally studied. Although a comprehensive assessment of overall protection efficacy of various mask materials and designs is not an easy task, given the large variations from various factors, not to mention the fit of a respirator/mask itself is subject dependent, a case study showing the comparison of material efficiency and overall efficacy, and its association with breathing resistance and other factors, it urgently needed under current pandemic.

Since the particles used in this study can not only represent the virus-laden particles but also, more importantly, the particulate air pollutant. The most concerning particulate pollutant is $\mathrm{PM}_{2.5}$ whose aerodynamic particle size is less than $2.5 \mu \mathrm{m}$. The particle size studied in this study falls into this size range. Hence, the conclusion of particle filtration efficiency and breathability of different common materials could also be applied when the general public DIY their masks to prevent particulate air pollutants. This is valuable for the countries suffering from air pollutions, especially developing countries with limited access to commercial masks. Under the current pandemic, the SARS-CoV-2 laden particle could cause acute respiratory disease, while the particulate air pollutant can also cause chronic respiratory diseases. According to many epidemiologic studies, the positive association between respiratory diseases and atmospheric pollutants has been proven. It is equally important for the general public to be protected from both the pathogens and ambient pollutants. The conclusions of this study can guide the general public when the commercial respiratory protection equipment is unavailable under a pandemic or a heavy air pollution episode.

\section{CONCLUSIONS}

In this study, we tested commercial respirators and masks, furnace filters, vacuum cleaner filters, and common household materials. We evaluated the materials' fractional filtration efficiency and breathing resistance, which are primary factors affecting respiratory protection. Neutralized monodisperse $\mathrm{NaCl}$ particles were used to measure the fractional efficiency. Breathing resistances were also compared at the same face velocity. To compare the efficiency-resistance tradeoff, the figure of merit of each tested common material was also calculated. Filter media with electrostatic charges (electret) is recommended due to its high efficiency with low flow resistance; multiple-layer household fabrics and sterilization wraps are acceptable materials; a coffee filter is inadvisable due to its low efficiency. The outcome of this study can not only offer guidance for the general public under the current pandemic but also suggest the appropriate alternative respiratory protection materials under heavy air pollution episodes.

\section{ACKNOWLEDGMENTS}

We would like to thank the support of members of the Center for Filtration Research: 3M Corporation, Applied Materials, Inc., BASF Corporation, Boeing Company, Corning Co., China Yancheng Environmental Protection Science and Technology City, Cummins Filtration Inc., Donaldson Company, Inc., Entegris, Inc., Ford Motor Company, Guangxi WatYuan Filtration System Co., Ltd, LG Electronics Inc., MSP Corporation; Parker Hannifin, Samsung Electronics Co., Ltd., Xinxiang Shengda Filtration Technology Co., Ltd., TSI Inc., W. L. Gore \& Associates, Inc., Shigematsu Works Co., Ltd., and the affiliate member National Institute for Occupational Safety and Health (NIOSH).

We would like to acknowledge the fruitful discussion we had with Professor Emeritus Yasuo Kousaka, Osaka Prefecture University, Sakai, Osaka, Japan; and with Dr. Michel Pourprix, French Alternative Energies and Atomic Energy Commission (CEA), Grenoble, France.

\section{REFERENCES}

3M (2020, March 23). Coronavirus and important things to know about airborne particles. https://www.filtrete.com/ 3M/en_US/filtrete/home-tips/full-story/ /coronavirus-andimportant-things-to-know-about-airborne-particles/?stor yid $=d 69 e 7735-c 02 c-46 d 2-9 c 8 a-a e 23372934 a c$

Anfinrud, P., Stadnytskyi, V., Bax, C.E. and Bax, A. (2020). Visualizing speech-generated oral fluid droplets with laser light scattering. N. Engl. J. Med. 382: 2061-2063.

ASHRAE (2017). ASHRAE Standard 52.2-2017 - Method of testing general ventilation air-cleaning devices for removal efficiency by particle size, Atlanta, GA.

ASTM International (2017). F2299/F2299M - 03(2017), 
Standard test method for determining the initial efficiency of materials used in medical face masks to penetration by particulates using latex spheres. ASTM International, West Conshohocken, PA. https://doi.org/10.1520/F2299_ F2299M-03R17

ASTM International (2019). ASTM F2101 - 19, Standard Test Method for Evaluating the Bacterial Filtration Efficiency (BFE) of Medical Face Mask Materials, Using a Biological Aerosol of Staphylococcus aureus. ASTM International, West Conshohocken, PA. https://doi.org/10. 1520/F2101-19

Bae, S., Kim, M.C., Kim, J.Y., Cha, H.H., Lim, J.S., Jung, J., Kim, M.J., Oh, D.K., Lee, M.K., Choi, S.H., Sung, M., Hong, S.B., Chung, J.W. and Kim, S.H. (2020). Effectiveness of surgical and cotton masks in blocking SARS-CoV-2: A controlled comparison in 4 patients. Ann. Intern. Med. 173: W22-W23. https://doi.org/10.732 6/m20-1342

Bourouiba, L., Dehandschoewercker, E. and Bush, J.W.M. (2014). Violent expiratory events: On coughing and sneezing. J. Fluid Mech. 745: 537-563. https://doi.org/10. 1017/jfm.2014.88

Bourouiba, L. (2020). Turbulent gas clouds and respiratory pathogen emissions: Potential implications for reducing transmission of COVID-19. JAMA 323: 1837-1838. https://doi.org/10.1001/jama.2020.4756

Brown, R.C. (1993). Air filtration: An integrated approach to the theory and applications of fibrous filters. Elsevier Science.

CDC (2020a). Clinical questions about COVID-19: Questions and answers. https://www.cdc.gov/coronavirus/ 2019-ncov/hcp/faq.html\#Transmission

CDC (2020b). How to make masks. https://www.cdc.g ov/coronavirus/2019-ncov/prevent-getting-sick/how-tomake-cloth-face-covering.html

CDC (2020c). Use of masks to help slow the spread of COVID-19. https://www.cdc.gov/coronavirus/2019-ncov/ prevent-getting-sick/diy-cloth-face-coverings.html

Cooper, D.W., Hinds, W.C., Price, J.M., Weker, R. and Yee, H.S. (1983). Common materials for emergency respiratory protection: Leakage tests with a manikin. Am. Ind. Hyg. Assoc. J. 44: 720-726. https://doi.org/10.1080/15298668 391405634

Davies, A., Thompson, K.A., Giri, K., Kafatos, G., Walker, J. and Bennett, A. (2013). Testing the efficacy of homemade masks: Would they protect in an influenza pandemic? Disaster Med. Public Health Prep. 7: 413418. https://doi.org/10.1017/dmp.2013.43

Food and Drug Administration (FDA) (2003). Surgical masks - premarket notification [510 (k)] submissions. Guidance for Industry and FDA. Rockville, MD: US Department of Health and Human Services. Food and Drug Administration. https://www.fda.gov/regulatoryinformation/search-fda-guidance-documents/surgicalmasks-premarket-notification-510k-submissions

Gralton, J., Tovey, E., McLaws, M.L. and Rawlinson, W.D. (2011). The role of particle size in aerosolised pathogen transmission: A review. J. Infect. 62: 1-13. https://doi.org/10.1016/j.jinf.2010.11.010
Greenhalgh, T., Schmid, M.B., Czypionka, T., Bassler, D. and Gruer, L. (2020). Face masks for the public during the covid-19 crisis. BMJ 369: m1435. https://doi.org/10. 1136/bmj.m1435

Halyard (2020). Can I use halyard sterilization wrap for DIY masks? https://www.halyardhealth.com/covid-19/diymasks.aspx

Howard, J., Huang, A., Li, Z., Tufekci, Z., Zdimal, V., van der Westhuizen, H.M., von Delft, A., Price, A., Fridman, L., Tang, L.H., Tang, V., Watson, G.L., Bax, C.E., Shaikh, R., Questier, F., Hernandez, D., Chu, L.F., Ramirez, C.M. and Rimoin, A.W. (2020). Face masks against COVID19: An evidence review. Preprints 2020: 2020040203. https://doi.org/10.20944/preprints202004.0203.v1

Johnson, D.F., Druce, J.D., Birch, C. and Grayson, M.L. (2009). A quantitative assessment of the efficacy of surgical and N95 masks to filter influenza virus in patients with acute influenza infection. Clin. Infect. Dis. 49: 275277. https://doi.org/10.1086/600041

Konda, A., Prakash, A., Moss, G.A., Schmoldt, M., Grant, G.D. and Guha, S. (2020). Aerosol filtration efficiency of common fabrics used in respiratory cloth masks. ACS Nano 14: 6339-6347. https://doi.org/10.1021/acsnano.0c 03252

Lai, A.C., Poon, C.K. and Cheung, A.C. (2012). Effectiveness of facemasks to reduce exposure hazards for airborne infections among general populations. J. R. Soc. Interface 9: 938-948. https://doi.org/10.1098/rsif.2011.0537

Leung, C.C., Lam, T.H. and Cheng, K.K. (2020a). Mass masking in the COVID-19 epidemic: People need guidance. Lancet 395: 945. https://doi.org/10.1016/S01406736(20)30520-1

Leung, N.H.L., Chu, D.K.W., Shiu, E.Y.C., Chan, K.H., McDevitt, J.J., Hau, B.J.P., Yen, H.L., Li, Y., Ip, D.K.M., Peiris, J.S.M., Seto, W.H., Leung, G.M., Milton, D.K. and Cowling, B.J. (2020b). Respiratory virus shedding in exhaled breath and efficacy of face masks. Nat. Med. 26: 676-680. https://doi.org/10.1038/s41591-020-0843-2

Liao, L., Xiao, W., Zhao, M., Yu, X., Wang, H., Wang, Q., Chu, S. and Cui, Y. (2020). Can N95 respirators be reused after disinfection? And for how many times? ACS Nano 14: 6348-6356. https://doi.org/10.1021/acsnano.0c03597

Littler Mendelson (2020). Facing your face mask duties - A List of statewide orders. https://www.littler.com/publicat ion-press/publication/facing-your-face-mask-duties-liststatewide-orders

MacIntyre, C.R., Seale, H., Dung, T.C., Hien, N.T., Nga, P.T., Chughtai, A.A., Rahman, B., Dwyer, D.E. and Wang, Q. (2015). A cluster randomised trial of cloth masks compared with medical masks in healthcare workers. BMJ Open 5: e006577. https://doi.org/10.1136/bmjopen2014-006577

Morawska, L. (2006). Droplet fate in indoor environments, or can we prevent the spread of infection? Indoor Air 16: 335347. https://doi.org/10.1111/j.1600-0668.2006.00432.x

Morawska, L., Johnson, G.R., Ristovski, Z.D., Hargreaves, M., Mengersen, K., Corbett, S., Chao, C.Y.H., Li, Y. and Katoshevski, D. (2009). Size distribution and sites of origin of droplets expelled from the human respiratory 
tract during expiratory activities. J. Aerosol Sci. 40: 256269. https://doi.org/10.1016/j.jaerosci.2008.11.002

Morawska, L. and Cao, J. (2020). Airborne transmission of SARS-CoV-2: The world should face the reality. Environ. Int. 139: 105730. https://doi.org/10.1016/j.envint.2020.1 05730

Morawska, L. and Milton, D.K. (2020). It is time to address airborne transmission of covid-19. Clin. Infect. Dis. https://doi.org/10.1093/cid/ciaa939

Mueller, A.V., Eden, M.J., Oakes, J.J., Bellini, C. and Fernandez, L.A. (2020). Quantitative method for comparative assessment of particle filtration efficiency of fabric masks as alternatives to standard surgical masks for PPE. medRxiv 2020.04.17.20069567. https://doi.org/10.1 101/2020.04.17.20069567

National Academies of Sciences, Engineering, and Medicine (NASEM) (2020). Rapid expert consultation on the effectiveness offabric masks for the COVID-19 Pandemic (April 8, 2020). The National Academies Press.

National Health Commission (2020). Guidelines for wearing masks for public. http://www.nhc.gov.cn/jkj/s3577/20200 3/0a472cc09e744144883db6a74fe6e760.shtml

National Health Commission and National Administration of Traditional Chinese Medicine (2020). Diagnosis and treatment protocol for novel coronavirus pneumonia (Trial Version 7). Chin. Med. J. 133: 1087-1095. https://doi.org/10.1097/cm9.0000000000000819

Office of the Federal Register (1995). Approval of respiratory protective devices. Code of Federal Regulations, Part 84, Title 42.

Ou, Q., Maricq, M.M. and Pui, D.Y.H. (2017). Evaluation of metallic filter media for sub-micrometer soot particle removal at elevated temperature. Aerosol Sci. Technol. 51: 1303-1312. https://doi.org/10.1080/02786826.2017.1 349871

Ou, Q., Pei, C., Kim, S.C., Abell, E. and Pui, D.Y.H. (2020). Evaluation of decontamination methods for commercial and alternative respirator and mask materials - view from filtration aspect. J. Aerosol Sci. 150: 105609. https://doi.org/10.1016/j.jaerosci.2020.105609

Prather, K.A., Wang, C.C. and Schooley, R.T. (2020). Reducing transmission of SARS-CoV-2. Science 368: 1422-1424. https://doi.org/10.1126/science.abc6197

Rengasamy, S., Eimer, B. and Shaffer, R.E. (2010). Simple respiratory protection-evaluation of the filtration performance of cloth masks and common fabric materials against 20-1000 nm size particles. Ann. Occup. Hyg. 54: 789-798. https://doi.org/10.1093/annhyg/meq044

RIDGID (2020). Ridgid's important notice. https://ww w.ridgid.com/us/en/vacuum-filters
Scharfman, B.E., Techet, A.H., Bush, J.W.M. and Bourouiba, L. (2016). Visualization of sneeze ejecta: Steps of fluid fragmentation leading to respiratory droplets. Exp. Fluids 57: 24. https://doi.org/10.1007/s00348-015-2078-4

Spurny, K.R. (1986). On the filtration of fibrous aerosols. Sci. Total Environ. 52: 189-199. https://doi.org/10.1016/ 0048-9697(86)90119-1

van der Sande, M., Teunis, P. and Sabel, R. (2008). Professional and home-made face masks reduce exposure to respiratory infections among the general population. PLoS One 3: e2618. https://doi.org/10.1371/journal.pone. 0002618

Wang, Q. and Yu, C. (2020). The role of masks and respirator protection against SARS-CoV-2. Infect. Control Hosp. Epidemiol. 41: 746-747. https://doi.org/10.1017/ic e.2020.83

World Health Organization (WHO) (2020a). Coronavirus disease (COVID-19) advice for the public: When and how to use masks. https://www.who.int/emergencies/diseases/ novel-coronavirus-2019/advice-for-public/when-and-howto-use-masks

World Health Organization (WHO) (2020b). Coronavirus disease (COVID-19) pandemic. https://www.who.int/em ergencies/diseases/novel-coronavirus-2019

Yang, C. (2012). Aerosol filtration application using fibrous media-An industrial perspective. Chin. J. Chem. Eng. 20: 1-9. https://doi.org/10.1016/S1004-9541(12)60356-5

Zhao, M., Liao, L., Xiao, W., Yu, X., Wang, H., Wang, Q., Lin, Y.L., Kilinc-Balci, F.S., Price, A., Chu, L., Chu, M.C., Chu, S. and Cui, Y. (2020). Household materials selection for homemade cloth face coverings and their filtration efficiency enhancement with triboelectric charging. Nano Lett. 20: 5544-5552. https://doi.org/10.1 021/acs.nanolett.0c02211

Zhu, N., Zhang, D., Wang, W., Li, X., Yang, B., Song, J., Zhao, X., Huang, B., Shi, W., Lu, R., Niu, P., Zhan, F., Ma, X., Wang, D., Xu, W., Wu, G., Gao, G.F., Tan, W. and China Novel Coronavirus Investigating Research Team (2020). A novel coronavirus from patients with pneumonia in China, 2019. N. Engl. J. Med. 382: 727733. https://doi.org/10.1056/NEJMoa2001017

Zuo, Z., Kuehn, T.H. and Pui, D.Y.H. (2013). Performance evaluation of filtering facepiece respirators using virus aerosols. Am. J. Infect. Control 41: 80-82. https://doi.org/ 10.1016/j.ajic.2012.01.010

Received for review, July 20, 2020 Revised, August 20, 2020 Accepted, August 28, 2020 